Pacific Journal of Mathematic 


\title{
CONDITIONS FOR ISOMORPHISM IN PARTIAL DIFFERENTIAL EQUATIONS
}

\author{
H. H. JOHNSON
}

This paper studies systems of linear homogeneous p. d. e. in two independent variables with constant coefficients. For such systems powerful algebraic tools are available to obtain results which may indicate patterns for more general systems. Linear isomorphism is defined, and necessary and sufficient conditions for linear isomorphism between two systems are found. This result is obtained from the infinite prolongation of the systems, and two systems are isomorphic if and only if their infinite prolongations are isomorphic. One unexpected result is the important role played by lower-order coefficients which do not appear in such classical notions as ellipticity, hyperbolicity or characteristics. The classification problem for these p.d.e. is reduced to a problem in linear algebra involving a finite number of relations.

Usually notions such as jets, exterior forms, linear bundles, etc., in $C^{\infty}$ or $C^{\omega}$ categories are used to express our definitions. Since we are concerned here with linear objects we shall use this opportunity to state the definitions in terms of linear algebra.

Let $z=\left(z^{1}, \cdots, z^{m}\right)$ be a point in the real vector space $V$. We denote $\partial_{j} z=\left(\partial_{j} z^{1}, \cdots, \partial_{j} z^{m}\right)$ where $j=1$ or 2 . Let $a$ and $b$ be real $m$ by $m$ matrices. Consider systems $\Sigma$ of the form $\partial_{2} z=\partial_{1} z a+z b$.

The total prolongation $P \Sigma$ of $\Sigma$ is the system $\partial_{2} z=z_{1} a+b$, $z_{1}=\partial_{1} z, \quad \partial_{2} z_{1}=\partial_{1} z_{1} a+z_{1} b$, where $z_{1}=\left(z_{1}^{1}, \cdots z_{1}^{m}\right)$. Let $P V$ denote the real vector space of $2 m$-tuples $\left(z, z_{1}\right)$. Observe that the equation $\partial_{2} z_{1}=\partial_{1} z_{1} a+z_{1} b$ is dictated by 'involutiveness' from $z_{1}=\partial_{1} z$, since $\partial_{2} z_{1}=\partial_{12} z=\partial_{1}\left(\partial_{1} z a+z b\right)$. If $z=f\left(x^{1}, x^{2}\right)$ is any solution of $\Sigma$ then $\left(z, z_{1}\right)=\left(f, \partial f / \partial x^{1}\right)$ is a solution of $P \Sigma$, and every solution of $P \Sigma$ arises in this way.

Similarly, $P^{2} \Sigma$ is the system on $P^{2} V=\left\{\left(z, z_{1}, z_{2}\right)\right\}, \partial_{2} z=z_{1} a+z b$, $\partial_{2} z_{1}=z_{2} a+z_{1} b, \partial_{2} z_{2}=\partial_{1} z_{2} a+z_{2} b, z_{1}=\partial_{1} z, z_{2}=\partial_{1} z_{1}$. Then $P^{n} \Sigma$ is defined similarly on $P^{n} V$. Finally, $P^{\infty} \Sigma$ is the system on $z_{\infty}=\left(z, z_{1}, z_{2}, \cdots\right)$

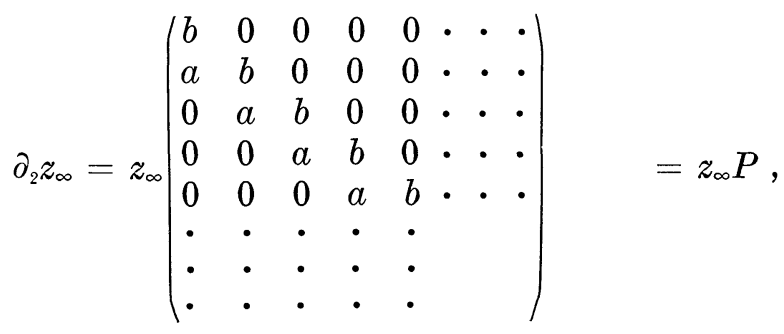




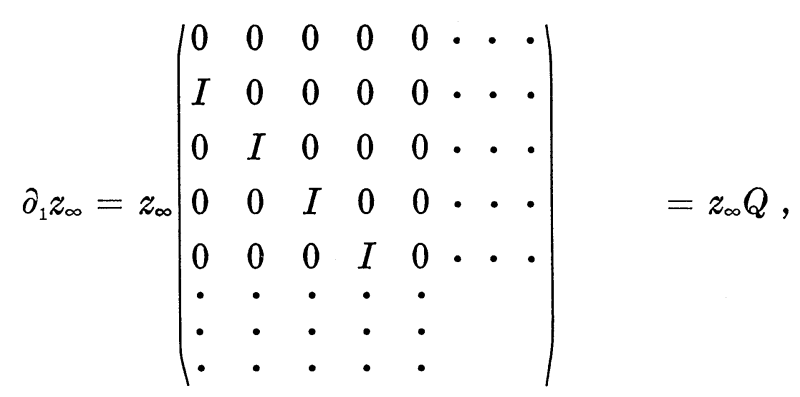

where a, $b, 0, I$ denote $m$ by $m$ real matrices, 0 the zero and $I$ the identity matrices.

We shall denote by $\Sigma^{\prime}$ a system $\partial_{2} y=\partial_{1} y c+y d$ where $y$ is a point in the real vector space $U$ and dimension $(U)=m^{\prime}$.

Definition 1. Two systems $\Sigma$ and $\Sigma^{\prime}$ are isomorphic if: (1) There is a linear transformation $\pi: P^{r} V \rightarrow U$,

$$
\pi\left(z, z_{1}, \cdots, z_{r}\right)=z k+z_{1} k_{1}+\cdots+z_{r} k_{r},
$$

where the $k_{j}$ are $m$ by $m^{\prime}$ matrices so that the 'pull-back' of the equations $\partial_{2} y=\partial_{1} y c+y d$ in $\Sigma^{\prime}$ are in $P_{r} \Sigma$. That is,

$$
\partial_{2} z k+\cdots+\partial_{2} z_{r} k_{r}=\left(\partial_{1} z k+\cdots \partial_{1} z_{r} k_{r}\right) c+\left(z k+\cdots+z_{r} k_{r}\right) d
$$

are equations in $P^{r} \Sigma$. Now if $z=f\left(x^{1}, x^{2}\right)$ is any solution of $\Sigma$ then $y=f k+\partial_{1} f k_{1}+\cdots+\partial_{1}^{r} f k_{r}$ is a solution of $\Sigma^{\prime}$.

(2) Similarly, there is a linear transformation $\rho: P^{S} U \rightarrow V$ so that the pull-back of $\partial_{2} z=\partial_{1} z a+z b$ is in $P^{s} \Sigma^{\prime}$.

(3) Finally, we require coherence in the following sense. Letting $p^{s} \pi: P^{r+s} V \rightarrow P^{s} U$ be defined by

$$
\begin{aligned}
p^{s} \pi\left(z, z_{1}, \cdots, z_{r+s}\right)=(z k & +\cdots+z_{r} k_{r}, z_{1} k+\cdots \\
& \left.+z_{r+1} k_{r}, \cdots, z_{s} k+\cdots+z_{r+s} k_{r}\right),
\end{aligned}
$$

we require that $\rho \circ p^{s} \pi\left(z, z_{1}, \cdots, z_{r+s}\right)=z$. This guarantees that if $z=f\left(x^{1}, x^{2}\right)$ is a solution of $\Sigma$ corresponding to the solution $y=g\left(x^{1}, x^{2}\right)$ of $\Sigma^{\prime}$ under $\pi$, then $g$ will correspond to $f$ under $\rho$. We also require that $\pi \circ p^{r} \rho\left(y, \cdots, y_{r+s}\right)=y$.

It is not difficult to generalize this to nonlinear systems using jet language. One may compare isomorphism with absolute equivalence. Using [2, Prop. 1] absolutely equivalent systems can be proved to be isomorphic.

DeFinition 2. Two systems $\Sigma$ and $\Sigma^{\prime}$ are infinitely isomorphic if there exists a matrix $K$ with countably infinite columns and rows such that 
(1) each column has all but a finite number of elements zero;

(2) $K^{-1}$ exists satisfying (1);

(3) the transformation $y_{\infty}=z_{\infty} K$ transforms $P^{\infty} \Sigma^{\prime}$ to $P^{\infty} \Sigma$, that is, $P^{\infty} \Sigma$ is the system $\partial_{2} z_{\infty}=z_{\infty} K P^{\prime} K^{-1}, \partial_{1} z_{\infty}=z_{\infty} K Q^{\prime} K^{-1}$ when $P^{\infty} \Sigma^{\prime}$ is $\partial_{2} y_{\infty}=y_{\infty} P^{\prime}, \partial_{1} y_{\infty}=y_{\infty} Q^{\prime}$.

Proposition 1. If $\Sigma$ and $\Sigma^{\prime}$ are isomorphic they are infinitely isomorphic.

Proof. From $\pi: P^{r} V \rightarrow U$ in Defintion 1 we obtain

by

$$
p^{\infty} \pi: P^{\infty} V \rightarrow P^{\infty} U
$$

$$
\begin{aligned}
p^{\infty} \pi\left(z_{\infty}\right)=(z k & +\cdots+z_{r} k_{r}, z_{1} k+\cdots \\
& \left.+z_{r+1} k_{r}, \cdots, z_{i} k+\cdots+z_{i+r} k_{r}, \cdots\right)
\end{aligned}
$$

which corresponds to a matrix $K$ with finite columns. Similarly $p^{\infty} \rho$ corresponds to a matrix $H$, and $H K=K H=I$ follows from condition (3) in Definition 1.

We now obtain an algebraic condition equivalent to infinite isomorphism.

THEOREM 1. Two systems $\Sigma$ and $\Sigma^{\prime}$ are infinitely isomorphic if and only if

(1) $m=m^{\prime}$,

(2) there exist $m$ by $m$ matrices $k, k_{1}, \cdots, k_{r}$ such that

$$
\begin{aligned}
b k & =k d, \\
b k_{1}+a k & =k c+k_{1} d, \\
b k_{2}+a k_{1} & =k_{1} c+k_{2} d, \\
& \vdots \\
b k_{r}+a k_{r-1} & =k_{r-1} c+k_{r} d, \\
a k_{r} & =k_{r} c,
\end{aligned}
$$

and (3) the infinite matrix

$$
K=\left(\begin{array}{lllllll}
k & 0 & 0 & 0 & \cdot & \cdot \\
k_{1} & k & 0 & 0 & \cdot & \cdot & \cdot \\
\cdot & k_{1} & k & 0 & \cdot & \cdot & \cdot \\
\cdot & \cdot & k_{1} & k & \cdot & \cdot & \cdot \\
\cdot & \cdot & \cdot & k_{1} & \cdot & \cdot \\
k_{r} & \cdot & \cdot & \cdot & & \\
0 & k_{r} & \cdot & \cdot \\
0 & 0 & k_{r} & \cdot & \\
\cdot & \cdot & \cdot & k_{r} & \\
\cdot & \cdot & \cdot & \cdot &
\end{array}\right)
$$


has a column-finite inverse.

Proof. Assume (1), (2) and (3). Then $K$ defines a linear transformation between $P^{\infty} V$ and $P^{\infty} U$, which gives an infinite isomorphism, since the equations in (2) are equivalent to $P K=K P^{\prime}$, and (1) implies $Q=Q^{\prime}$ while it is easy to check that $Q K=K Q$.

Conversely, if $K$ is a matrix defining an isomorphism between $P^{\infty} \Sigma$ and $P^{\infty} \Sigma^{\prime}$, then $P K=K P^{\prime}$ and $Q K=K Q^{\prime}$. Let $W$ be the real vector space of countably infinite column vectors whose components are all zero except possibly a finite number. These matrices $P, Q, K$ can be regarded as linear transformations on $W$ to itself.

Then $K$ defines a linear transformation, $K_{0}$, on $W / Q^{\prime}(W)$ to $W / Q(W)$ by $K_{0}\left(w+Q^{\prime}(W)\right)=K(w)+Q(W)$, since if $w=Q^{\prime}(v)$ then $K(w)=K Q^{\prime}(v)=Q K(v)$. This $K_{0}$ is onto because $K$ is onto (it has an inverse), and $K_{0}$ is one-to-one because if

$$
K(w)=Q(v)=Q K\left(v_{1}\right)=K Q^{\prime}\left(v_{1}\right),
$$

then $w=Q^{\prime}\left(v_{1}\right)$.

Since $W / Q(W)$ is isomorphic to $W / Q^{\prime}(W)$, their dimensions are the same. But the dimension of $W / Q(W)$ is $m$, since and vector $\left(v_{1}, v_{2}, \cdots\right)^{t}$, where the $v_{i}$ are 1 by $m$, may be expressed as

$$
\left(v_{1}, 0,0, \cdots\right)^{t}+Q\left(v_{2}, v_{3}, \cdots\right)^{t} .
$$

Similarly for $Q^{\prime}$. Hence $m=m^{\prime}$.

From $Q K=Q^{\prime} K=K Q^{\prime}$, if one partitions $K$ into $m$ by $m$ submatrices, it is immediate that $K$ must have the form in (3). Then relations (2) follow at once from $P K=K P^{\prime}$.

THEOREm 2. If $P^{\infty} \Sigma$ and $P^{\infty} \Sigma^{\prime}$ are infinitely isomorphic, then $\Sigma$ and $\Sigma^{\prime}$ are isomorphic.

Proof. Let $k, k_{1}, \cdots, k_{r}$ be as in Theorem 1. Then $\pi: P^{r} V \rightarrow U$ defined by $\pi\left(z, z_{1}, \cdots, z_{r}\right)=z k+z_{1} k_{1}+\cdots+z_{r} k_{r}$ satisfies

$$
\begin{aligned}
\partial_{2}(z k & \left.+z_{1} k_{1}+\cdots+z_{r} k_{r}\right)-\partial_{1}\left(z k+\cdots+z_{r} k_{r}\right) c \\
& -\left(z k+\cdots+z_{r} k_{r}\right) d \\
\equiv & \left(z_{1} a+z b\right) k+\left(z_{2} a+z_{1} b\right) k_{1}+\cdots+\left(\partial_{1} z_{r} a+z_{r} b\right) k_{r} \\
& -\left(z_{1} k+z_{2} k_{1}+\cdots+z_{r} k_{r-1}+\partial_{1} z_{r} k_{r}\right) c-\left(z k+z_{1} k_{1}\right. \\
& \left.+\cdots+z_{r} k_{r}\right) d \quad\left(\text { modulo } P^{r} \Sigma\right) \\
= & z(b k-k d)+z_{1}\left(a k+b k_{1}-k c-k_{1} d\right) \\
& +\cdots+z_{r}\left(a k_{r-1}+b k_{r}-k_{r-1} c-k_{r} d\right)+\partial_{1} z_{r}\left(a k_{r}-k_{r} c\right)=0 .
\end{aligned}
$$

Thus condition (1) of Definition 1 is satisfied. 
If $H=K^{-1}$ the analogous relations for $H$ define $\rho: P^{s} U \rightarrow V$ which satisfies condition (2) of Definition 1. Finally, condition (3) follows from $H K=K H=I$.

COROLlaRY. In order that $\Sigma$ and $\Sigma^{\prime}$ be isomorphic it is necessary that $m=m^{\prime}$ and $b$ be similar to $d$.

Proof. The matrix $K^{-1}$ exists only if $k^{-1}$ exists, so $k^{-1} b k=d$.

This last observation shows the importance of the $O$-order coefficients, which is rather unexpected in light of the classical notions such as characteristics which are invariants but in which $b$ plays no part $[3,4,5]$.

Observe that if $\Sigma$ and $\Sigma^{\prime}$ are isomorphic using the relations in Theorem 2, then from $a k_{r}=k_{r} c$ one sees that for any eigenvector $v$ of $c, a k_{r} v=k_{r} c v=\lambda k_{r} v$, so $k_{r} v$ is an eigenvector of a belonging to the same eigenvalue provided $k_{r} v \neq 0$. The author conjectures that in all cases the eigenvalues of $\Sigma$ and $\Sigma^{\prime}$ coincide.

EXAMPLE 1. If $\Sigma$ is $\partial_{2} z^{1}=z^{1}, \partial_{2} z^{2}=\partial_{1} z^{1}$ and $\Sigma^{\prime}$ is $\partial_{2} y^{1}=y^{1}$, $\partial_{2} y^{2}=0$, then taking $r=0$ and

$$
k=\left(\begin{array}{ll}
0 & 1 \\
0 & 0
\end{array}\right)
$$

we find $\Sigma$ and $\Sigma^{\prime}$ isomorphic. The Cauchy problem for $\Sigma$ with initial data $z^{1}\left(x^{1}, 0\right)=\varphi\left(x^{1}\right)$ and $z^{2}\left(x^{1}, 0\right)=\psi\left(x^{1}\right)$ is well-posed, for its solution is $z^{1}=\varphi\left(x^{1}\right) \exp \left(x^{2}\right), z^{2}=\varphi^{\prime}\left(x^{1}\right) \exp \left(x^{2}\right)+\psi\left(x^{1}\right)-\varphi^{\prime}\left(x^{1}\right)$.

ExAMPLE 2. Now let $\Sigma$ be $\partial_{2} z^{1}=z^{2}, \partial_{2} z^{2}=\partial_{1} z^{1}$ and $\Sigma^{\prime}$ be

$$
\partial_{2} y^{1}=y^{2}, \partial_{2} y^{2}=0 \text {. }
$$

These systems are not isomorphic, for $\Sigma^{\prime}$ has solutions

$$
y^{1}=x^{2} \psi\left(x^{1}\right)+\varphi\left(x^{1}\right), y^{2}=\psi\left(x^{1}\right),
$$

while $\Sigma$ is equivalent to $\partial_{22} z^{1}=\partial_{1} z^{1}$, whose solution for $z^{1}\left(x^{1}, 0\right)=0$, $z^{2}\left(x^{1}, 0\right)=\psi\left(x^{1}\right)$ requires $\psi$ that be infinitely differentiable [1, p.27].

\section{REFERENCES}

1 J. Hadamard, Lectures on Cauchy's Problem in Linear Partial Differential Equations, Dover, New York (1952).

2. H. H. Johnson, Absolute equivalence of exterior differential systems, Illinois J. Math., 10 (1966), 407-411.

3. - The non-invariance of hyperbolicity for partial differential equations, Pacific J. Math., 22 (1967) 419-430. 
4. - Determınation of hyperbolicity by partial prolongations, Pacific J. Math., 30 (1969) 670-695.

5. - Partial prolongations and characteristics of differential equations, Trans. Amer. Math. Soc., 146 (1969), 231-240.

Received September 21, 1970.

UNIVERSITY OF WASHINGTON 


\title{
PACIFIC JOURNAL OF MATHEMATICS
}

\author{
EDITORS
}

\author{
H. SAMELSON \\ Stanford University \\ Stanford, California 94305

\section{R. HOBBY} \\ University of Washington \\ Seattle, Washington 98105
}

J. DUGUNDJI

Department of Mathematics

University of Southern California

Los Angeles, California 90007

RICHARD ARENS

University of California

Los Angeles, California 90024

\section{ASSOCIATE EDITORS}
E. F. BECKENBACH
B. H. NeUmanN
F. WoLF
K. YoshidA

\section{SUPPORTING INSTITUTIONS}

\author{
UNIVERSITY OF BRITISH COLUMBIA \\ CALIFORNIA INSTITUTE OF TECHNOLOGY \\ UNIVERSITY OF CALIFORNIA \\ MONTANA STATE UNIVERSITY \\ UNIVERSITY OF NEVADA \\ NEW MEXICO STATE UNIVERSITY \\ OREGON STATE UNIVERSITY \\ UNIVERSITY OF OREGON \\ OSAKA UNIVERSITY \\ UNIVERSITY OF SOUTHERN CALIFORNIA
}

\author{
STANFORD UNIVERSITY \\ UNIVERSITY OF TOKYO \\ UNIVERSITY OF UTAH \\ WASHINGTON STATE UNIVERSITY \\ UNIVERSITY OF WASHINGTON \\ $* * * *{ }^{*}$
AMERICAN MATHEMATICAL SOCIETY
CHEVRON RESEARCH CORPORATION
NAVAL WEAPONS CENTER
}

The Supporting Institutions listed above contribute to the cost of publication of this Journal, but they are not owners or publishers and have no responsibility for its content or policies.

Mathematical papers intended for publication in the Pacific Journal of Mathematics should be in typed form or offset-reproduced, (not dittoed), double spaced with large margins. Underline Greek letters in red, German in green, and script in blue. The first paragraph or two must be capable of being used separately as a synopsis of the entire paper. The editorial "we" must not be used in the synopsis, and items of the bibliography should not be cited there unless absolutely necessary, in which case they must be identified by author and Journal, rather than by item number. Manuscripts, in duplicate if possible, may be sent to any one of the four editors. Please classify according to the scheme of Math. Rev. Index to Vol. 39. All other communications to the editors should be addressed to the managing editor, Richard Arens, University of California, Los Angeles, California, 90024.

50 reprints are provided free for each article; additional copies may be obtained at cost in multiples of 50 .

The Pacific Journal of Mathematics is published monthly. Effective with Volume 16 the price per volume (3 numbers) is $\$ 8.00$; single issues, $\$ 3.00$. Special price for current issues to individual faculty members of supporting institutions and to individual members of the American Mathematical Society: $\$ 4.00$ per volume; single issues $\$ 1.50$. Back numbers are available.

Subscriptions, orders for back numbers, and changes of address should be sent to Pacific Journal of Mathematics, 103 Highland Boulevard, Berkeley, California, 94708.

PUBLISHED BY PACIFIC JOURNAL OF MATHEMATICS, A NON-PROFIT CORPORATION

Printed at Kokusai Bunken Insatsusha (International Academic Printing Co., Ltd.), 270, 3chome Totsuka-cho, Shinjuku-ku, Tokyo 160, Japan. 


\section{Pacific Journal of Mathematics}

Vol. 39, No. $2 \quad$ June, 1971

Edward Arthur Bertram, Permutations as products of conjugate infinite

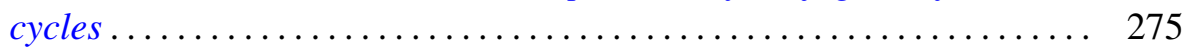

David Blair, Almost contact manifolds with Killing structure tensors ...... 285

Bruce Donald Calvert, Nonlinear equations of evolution ............. 293

Bohumil Cenkl and Giuliano Sorani, Cohomology groups associated with

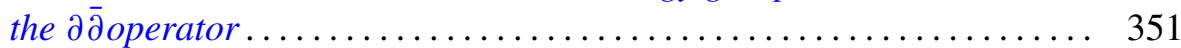

Martin Aaron Golubitsky and Bruce Lee Rothschild, Primitive subalgebras

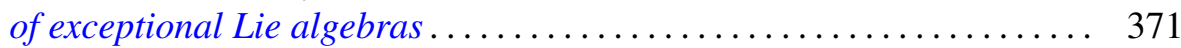

Thomas J. Jech, Two remarks on elementary embeddings of the universe ... 395

Harold H. Johnson, Conditions for isomorphism in partial differential equations........................................ 401

Solomon Leader, Measures on semilattices ..................... 407

Donald Steven Passman, Group rings satisfying a polynomial identity. II .......................................... 425

Ralph Tyrrell Rockafellar, Integrals which are convex functionals. II . . . . . 439

Stanisław Sławomir Świerczkowski, Cohomology of group germs and Lie

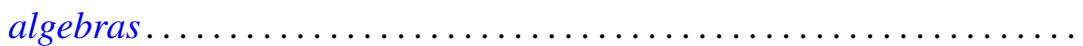

John Griggs Thompson, Nonsolvable finite groups all of whose local subgroups are solvable. III ............................ 483

Alan Curtiss Tucker, Matrix characterizations of circular-arc graphs .... 535 